\title{
IDENTIDADE, DIFERENÇA E COERÊNCIA REFLEXÕES CRÍTICAS SOBRE A METALÓGICA DE CIRNE-LIMA
}

Guido Imaguire*

SINTESE - Neste artigo analiso criticamente a metalógica proposta por Cime-Lima com seus três principios fundamentais: Identidade, Diferença e Coerência. Estes são considerados universalíssimos, pois precisam ser aplicados a absolutamente tudo, inclusive a si mesmos. Disso surge a antinomia que legitima uma passagem dialética para a Filosofia da Natureza. Mostrarei: (1) que a fundamentação do principio de Diferença é falaciosa, e (2) que esta metalógica gera artificialmente antinomias por meio de um uso inadequado da noção de auto-aplicação. PALAVRAS-CHAVE - Identidade. Diferença. Coerência.
ABSTRACT - In this article I analyze critically the meta-logic proposed by Cime-Lima, which includes three fundamental principles: Identity, Difference and Coherence. These are considered absolutely universal because they must be applied to everything including themselves. From this, he creates an antinomy which should legitimate a dialectical transition to Philosophy of the Nature. I will show that (1) the argument for the introduction of the principle of Difference is fallacious, and (2) that this meta-logic generates antinomies only artificially due to an inadequate use of the notion of self-application.

KEY WORDS - Identity. Difference. Coherence.

Poucos filósofos contemporâneos têm a pretensão de construir um sistema holístico que seja capaz de dar conta de inúmeros problemas da filosofia de modo sistemático e coerente, como o filósofo brasileiro Carlos Cirne-Lima. Desafiar ortodoxias e modismos é uma prática saudável que deveria ser cultivada no meio de todas as ciências críticas, em especial na filosofia. Neste sentido, dedico este artigo à análise do sistema proposto por este autor no texto $O$ Absoluto e o sistema: Agostinho, Tomás de Aquino e Hegel, capítulo do livro O Deus dos Filósofos Modernos (Oliveira e Almeida, Vozes, 2002), em especial do que ele designa "metalógica".

Cirne-Lima inicia a construção do seu sistema com a metalógica compreendida como disciplina que analisa os pressupostos de todo e qualquer discurso racional, inclusive, e em especial, do discurso lógico-argumentativo. A metalógica não pretende estabelecer um conjunto intersecção de axiomas ou princípios comuns a

* Professor da UFC (Universidade Federal do Ceará).

\begin{tabular}{|l|l|l|l|l|l|}
\hline VERITAS & Porto Alegre & v. 48 & n. 4 & Dezembro 2003 & p. 533-547 \\
\hline
\end{tabular}


todos os sistemas lógicos nem estudar questões do que se convencionou chamar na tradição analítica de "filosofia da lógica", tal como praticam Quine em Philosophy of Logic e Susan Haack em The Philosophy of Logics. A metalógica de CirneLima é uma espécie de estudo transcendental ou propedêutico da lógica, na medida em que analisa as condições de possibilidade de todo e qualquer discurso.

Segundo Cirne-Lima a metalógica tem apenas um princípio fundamental, composto de três momentos: Identidade, Diferença e Coerência. A motivação mais profunda para a tese da unicidade dos três momentos parece consistir na noção da co-originalidade e mútua auto-aplicação dos princípios, que é central para o seu sistema, pois é assim que ele infere a antinomia que gera o movimento, e assim, a dinâmica interna do sistema. Como a necessidade da mútua autoaplicação decorre automaticamente da sua universalidade irrestrita, e até mesmo por motivos puramente estilísticos, referir-me-ei neste artigo aos "três princípios" ao invés de "três momentos do princípio (único) metalógico".

\section{Princípios da Metalógica}

\subsection{Princípio de Identidade (PI)}

O primeiro princípio proposto é o Princípio de Identidade, o qual afirma uma tautologia do tipo $\mathrm{A}=\mathrm{A}$. Como o autor admite qualquer afirmação de identidade como sendo uma tautologia, concluo que ele considera verdadeiro o enunciado universal $\forall \mathrm{x}(\mathrm{x}=\mathrm{x})$ da lógica clássica, expresso informalmente como "tudo é idêntico a si mesmo", mas que esta fórmula no seu sentido habitual é apenas um caso particular do seu princípio mais universal. O PI de Cirne-Lima não é mera expressão deste princípio consensualmente aceito pela lógica standard, pois enquanto a fórmula $\forall \mathrm{x}(\mathrm{x}=\mathrm{x})$ é normalmente restrita, na medida em que é restrito o âmbito de objetos sobre o qual a variável x percorre, para Cirne-Lima x é uma variável completamente irrestrita que percorre sobre todo o universo do ser e/ou do discurso, inclusive sobre o próprio princípio $\mathrm{PI}$, de modo que é válido $\mathrm{PI}=\mathrm{PI}$.

Embora a noção de variável universal irrestrita seja considerada hoje uma espécie de "monstro sintático", posto ser responsável pela geração de fórmulas sintaticamente malformadas na medida em que não diferencia nem diferentes tipos lógicos nem diferentes níveis da linguagem, aceito para fins de argumentação este princípio no sentido proposto. ${ }^{2}$ Suponho que para Cirne-Lima, a metalógica está "fora" do âmbito da lógica, pois a lógica, devido ao atual desenvolvimento de uma pluralidade de sistemas diferentes, passou a ser uma ciência

Nos primórdios da lógica contemporânea, numa fase hoje considerada ingênua, encontramos algumas vezes noções semelhantes a esta variável absolutamente universal. Tendo em vista a convicção de que a lógica é um sistema único e universalíssimo, o próprio Russell simpatizou com esta noção, especialmente porque a restrição de âmbito podia ser feita predicativamente na própria fórmula: ao invés de $\forall x$ ( $x$ é par ou ímpar) subentendendo uma restrição do âmbito da variável aos números naturais, poder-se-ia afirmar $\forall x$ ( $x$ é número natural $\rightarrow x$ é par ou impar), onde $x$ percorre todo o universo platônico do Ser. 
particular, não universal, e portanto inadequada para uma discussão propedêutica a uma ciência universal. Creio que esta concepção está baseada num engano fundamental. Da pluralidade de sistemas lógicos não decorre a possibilidade de nos colocarmos "fora" da lógica (ou "fora de qualquer sistema lógico") - como diria Wittgenstein, pensar ilogicamente é, a rigor, não pensar - e, portanto, para pensar a metalógica precisamos de uma lógica, por mais particular que esta seja. Não podemos pretender situarmo-nos numa região "alógica" (para além do lógico e do ilógico): Isso equivaleria a colocar-se fora da racionalidade, e isso, certamente, não pretende Cirne-Lima. No seu texto de fundamentação da metalógica Cirne-Lima usa argumentos, aliás, que seguem argumentações da lógica clássica: "uma tautologia é necessariamente verdadeira" (p. 57), "para fazer Lógica são precisos, além da tautologia, outros axiomas" (p. 58), "se uma proposição afirmativa universal é verdadeira a correspondente proposição contrária é falsa" (p. 60), etc. Além disto, ele faz uso de argumentos transcendentais (mostrarei isso mais adiante) - e pode-se usar um argumento transcendental para rejeitar a pretensão de se situar fora da lógica: se por lógica se compreende estrutura argumentativa (mesmo que particular), como argumentar em prol de uma metalógica, ou até mesmo, argumentar em favor de uma região "além das lógicas" fora de uma estrutura argumentativa? A argumentação particular de Cirne-Lima é, em última instância, uma argumentação lógica (no sentido particular da palavra), e não metalógica. Mas, novamente, para fins de argumentação aceitarei a noção de Cirne-Lima princípio universal irrestrito, pois pretendo formular uma critica imanente, interna.

Uma questão logicamente relevante para a discussão posterior é a decisão sobre a aridade do predicado "ser idêntico". Por aridade entende-se, em geral, o número de argumentos a serem preenchidos para que uma proposição seja significativa, ou seja, para que uma fórmula qualquer seja sintaticamente bem formada. O predicado "é mortal" tem aridade 1, pois basta um argumento para a proposição ser bem formulada, p. ex.: "Sócrates é mortal", tradicionalmente expresso em fórmulas do tipo " $F(x)$ ", muitas vezes com índices " $F(x)$ ", mas que eu, por motivos de melhor visualização, representarei com " $F$...". O predicado "ama" tem aridade 2, pois precisa de dois argumentos para tornar a proposição sintaticamente correta, p. ex.: "Pedro ama Maria", tradicionalmente expresso em fórmulas do tipo " $R(x, y)$ " ou " $x R y$ " (onde $x$ e y podem ser idênticos: "Pedro ama a si mesmo"), muitas vezes com índices " $\mathrm{R}^{2}(\mathrm{x}, \mathrm{y})$ ", mas que eu, por motivos de melhor visualização, representarei com "__ R...".

A questão importante no caso do PI é, então: qual a aridade de "ser idêntico"? A dificuldade da questão foi bem formulada por Russell:

The question whether identity is or is not a relation, and even whether there is such a concept at all, is not easy to answer. For, it may be said, identity cannot be a relation, since, where it is truly asserted, we have only one term, whereas two terms are required for a relation. (PoM § 64) 
Cirne-Lima considera, de modo habitual, a identidade um predicado de aridade 2: "__ = ...", p.ex. "Túlio = Cícero". Numa linguagem segundo o ideal do Tractatus de Wittgenstein, porém, onde para cada indivíduo do domínio das variáveis só existe um nome próprio, pode-se concluir que "dizer de duas coisas, que elas são idênticas é um contra-senso e dizer de uma coisa que ela é idêntica a si mesma não é dizer rigorosamente nada" (TLP 5.5303). Isto se baseia na intuição correta, segundo a qual a identidade só é uma relação binária em nível do simbolismo, na medida em que existem no simbolismo expressões co-referenciais, mas em nivel ontológico, a identidade não é uma relação binária, mas sim um predicado monádico, do tipo "IX" - significando I "ser idêntico a si mesmo". Isto será fundamental para nossa análise e crítica posterior. Os dois próximos princípios, sim, envolverão relações binárias.

\subsection{Princípio de Diferença (PD)}

Outras dificuldade surgem quando Cirne-Lima passa para a análise do Princípio de Diferença. Segundo Cirne-Lima:

O segundo subprincipio da Metalógica diz que, além do A, identidade simples, identidade iterativa e identidade reflexa, há na linguagem outras entidades como o B, ० C, o D..., como a disjunção, a conjunção, a implicação etc., como as variáveis lógicas. Há também, inarredável e irremovivel, o ato de fala. (2002, p. 58)

Aparecem aqui duas perspectivas diferentes que Cirne-Lima distingue, com razão, de maneira clara: uma estritamente lógica (ou metalógica) e outra pragmática. Porém, mesmo fazendo a distinção entre pressuposto pragmático e (meta-)lógico, ele insiste em unificar ambos num só princípio, o que é filosoficamente um procedimento perigoso. Esta mistura de níveis ou dimensões é fundada num passo falacioso, que é a base do seu argumento para a necessidade de tal princípio. Prossigo analisando minuciosamente o texto, e para facilitar a análise, enumero as frases para examiná-las depois:

(1) O Princípio da Diferença - assim o chamo - expressa também condições necessárias de possibilidade de toda e qualquer fala que vá além da mera tautologia. (2) Ele expressa e explicita - e isto é aqui de grande importância - a necessidade do ato de fala, que, embora em si contingente, é condição necessária de possibilidade da linguagem. (3) A necessidade lógica da proposição tautológica, para ser expressa em linguagem, pressupõe sempre, como condição necessária, a existência contingente de algum ato de fala. (4) A necessidade, aqui, pressupõe como seu fundamento a facticidade do ato de fala contingente. (5) Em outras palavras e com rigor ainda maior: A existência contingente do ato de fala é condição necessária de possibilidade para que a necessidade lógica da proposição tautológica venha a ser expressa em linguagem. (6) A necessidade, aqui, depende da facticidade contingente; como, aliás, nos primeiros axiomas das lógicas modais, onde a possibilidade e a necessidade de $\mathrm{p}$ são derivadas da facticidade de p. (2002, p. 58)

Basicamente, a falácia consiste numa mistura de duas teses diferentes, facilmente confundíveis, mas que precisam ser claramente distintas, a saber: 
(A) A expressão da tautologia em linguagem pressupõe sempre como condição necessária a existência contingente de um ato de fala.

(B) A necessidade lógica da verdade da tautologia pressupõe como sua condição necessária a existência contingente de um ato de fala.

É claro que $(\mathrm{A})$ e $(\mathrm{B})$ são diferentes teses: $\mathrm{A}$ tese $(\mathrm{A})$ diz respeito à pragmática e é trivialmente verdadeira, pois afirma que a expressão de uma tautologia pressupõe um ato de fala. Isso é evidente por si só, por assim dizer, uma tautologia, pois a expressão em linguagem de qualquer coisa é justamente um ato de fala, um pronunciamento, de modo que (A) é uma simples afirmação de identidade. A tese (B), por sua vez, diz respeito à lógica, e expressa que a necessidade lógica da tautologia (e não a sua expressão, como em (A)) pressupõe a existência de um ato de fala contingente. Isso não é óbvio, nem verdadeiro. $\mathrm{E}$, acima de tudo, (B) não decorre de (A): de uma necessidade para a expressão não se pode deduzir a necessidade da verdade do expresso.

Cirne-Lima quer fundamentar (B), mas seu argumento se limita sempre à fundamentação de (A), chegando ao final, subrepticiamente à conclusão de (B). Vejamos em detalhe: (1) expressa a tese (A), pois trata das "condições necessárias de possibilidade de toda e qualquer fala". Em (2) ele reforça e afirma, com razão, "a necessidade do ato de fala, que, embora em si contingente, é condição necessária de possibilidade da linguagem". Aqui ainda nos movemos no âmbito da tese pragmática (A). É interessante observar que o uso constante da expressão "condição de possibilidade" revela a natureza transcendental da sua argumentação, cuja forma implícita seria: "quem afirma não haver nada além da tautologia, já comete um engano, pois sua afirmação fática não é idêntica à tautologia que ele afirma". Em (3) começa sutilmente a costura das duas teses: "A necessidade lógica da proposição tautológica, para ser expressa em linguagem, pressupõe sempre, como condição necessária, a existência contingente de algum ato de fala.". Se levarmos a sério a cláusula "para ser expressa em linguagem", então (3) equivale a (A): 0 ato de fala é a condição necessária da expressão da tautologia. Mas a formulação de (3) sugere, já sutilmente, que o ato de fala é condição de possibilidade da necessidade da verdade da tautologia. Mas é claro que o ato de fala é condição para que a tautologia seja expressa, e não para que ela seja necessariamente verdadeira. Em (4) ele fecha a costura das duas teses: "A necessidade, aqui, pressupõe como seu fundamento a facticidade do ato de fala contingente", o que já é expressão clara de (B): a facticidade de ato de fala é condição da necessidade - e ele subentende aqui a necessidade da verdade da tautologia. Em (5) ele dá um passo atrás para reintroduzir a noção pragmática, que, claro, é mais convincente, pois, como dito acima, é uma tautologia, reforçando assim o seu argumento retoricamente. Com razão ele diz que a afirmação tem mais rigor: "Em outras palavras e com rigor ainda maior: A existência contingente do ato de fala é condição necessária de possibilidade para que a necessidade lógica da proposição tautológica venha a ser expressa em linguagem." De fato, o rigor aumenta, pois (5) é verdade, pois afirma simplesmente (A), a necessidade do ato de fala para a expressão do 
que se pretende dizer. Mas é errado supor que isso é o mesmo que (4), meramente dito "em outras palavras". A suma em (6) reza que a necessidade depende da facticidade: "A necessidade, aqui, depende da facticidade contingente; como, aliás, nos primeiros axiomas das lógicas modais, onde a possibilidade e a necessidade de p são derivadas da facticidade de p". A questão é: qual necessidade? A da expressão em relação ao ato de fala (o que é óbvio), ou a da verdade da tautologia em relação ao ato de fala (o que é falso)? Parece, novamente, que ele se refere à necessidade da verdade da tautologia, pois ele fala dos "primeiros axiomas das lógicas modais", nos quais só se trata da necessidade da verdade da proposição e nunca da necessidade de enunciação da proposição - este aspecto pragmático não integra nenhum sistema lógico modal conhecido. Aliás, de fato, as lógicas modais modernas aceitam o princípio conhecido desde a escolástica ad esse ab posset valet consequentia, mas somente num sistema radicalmente necessitarista (como o de Espinoza) se afirmaria que a necessidade é derivada da facticidade (de "Carlos Cirne-Lima é um bom judoca" não se segue "Carlos Cirne-Lima é necessariamente um bom judoca"). Não há nenhum fundamento nas lógicas modais para derivação da necessidade a partir da factualidade, muito menos para a factualidade do ato contingente de fala.

Em manifestação pessoal posterior, Cirne-Lima afirma nunca ter pretendido defender (B), mas tão somente (A). O que Cirne-Lima pretende rejeitar nesta passagem, porém, não é a trivialidade de (A) na interpretação acima sugerida, mas sim a noção de uma Lógica "platônica" que "paira no ar" e existe independentemente do fazer dos lógicos nos gabinetes empoeirados dos departamentos de filosofia, matemática ou computação. Este é um aspecto certamente controverso ${ }^{2}$ (a pergunta "existe a lógica?" faz sentido? Qual sentido de existir aqui?) e, parece-me, ainda mais problemático para o sistema de Cirne-Lima que pretende construir o contingente da natureza (com seres humanos, incluindo lógicos) a partir da metalógica. Mesmo que não houvesse lógica sem lógicos, valeria o mesmo para a metalógica? Afinal, segundo Cirne-Lima, ela está além das lógicas particulares (estas podem ser dependentes de lógicos barbudos). A metalógica pode, por sua vez, depender dos metalógicos, mesmo sendo esta metalógica o motor a partir do qual emergem contingentes do real? Mesmo que aceitemos isso (afinal, esta dimensão pragmática é fundamentada dentro da metalógica), daí somente segue um sentido especifico do PD: a diferença entre o nexo metalógico tautológico e o pragmático, e não um princípio universalíssimo que possa ser aplicado sobre nexos ou princípios lógicos, fora da dimensão pragmática, que é justamente o que Cirne-Lima faz na auto-aplicação

\footnotetext{
Esta controvérsia é freqüentemente formulada em termos da questão "as verdades matemáticas e lógicas são descobertas ou criadas pelos matemáticos e lógicos?" Para os pioneiros da lógica analítica, Frege, Russell (veja PoM § 427) e o primeiro Wittgenstein, bem como para Gödel, a tese de dependência da Lógica em relação aos lógicos seria certamente rejeitada. A partir da reviravolta pragmática do segundo Wittgenstein, bem como da lógica construtivista de Brower e Heyting isso se tornou mais amplamente aceito. A discussão contemporânea em tomo do platonismo na matemática foi inaugurada com o artigo clássico de Paul Bernays "Sur le platonisme dans les mathématiques" (1935 em: L'Enseignement Mathématique, Vol. XXXIV, Nr. 1-2).
} 
dos princípios, cerne de toda sua argumentação. A tese da universalidade do PD seria baseado numa indução fraquíssima: de "a expressão da tautologia depende da pragmática, que é diferente da tautologia" para "absolutamente tudo é diferente de absolutamente tudo" (PD compreendido como universalíssimo).

$\mathrm{O}$ PD é desmembrado em três itens, sendo o terceiro este que analisamos (o contingente ato de fala como alteridade em relação à tautologia). O primeiro item afirma a existência de uma pluralidade - e assim, de alteridade ou diferença - de operadores lógicos como a implicação, a disjunção, etc. Este item não é, a rigor, correto, pelo menos não como fundamentação da necessidade da alteridade, postas as possibilidades conhecidas de redução de todos os conectivos (inclusive do conectivo monádico da negação) ao conectivo de Sheffer e, igualmente, ao de Peirce. Ao invés de $\mathrm{A} \rightarrow \mathrm{A}$ poderíamos escrever $\mathrm{A} \mid(\mathrm{A} \mid \mathrm{A})$, e assim por diante.

No desenvolvimento posterior do seu texto, Cirne-Lima parece sugerir uma tese contrária a (B). Ele lança a questão se o PD poderia ser derivado do PI, e neste, caso, não precisaria ser suposto como co-originário, como suspeitaram Platão, Fichte, Schelling e aparentemente Hegel. Ele apresenta reflexões interessantes, em especial a sua conclusão de que "pelo menos meu ato de fala, em sua facticidade contingente, não está pré-programado no Princípio de Identidade" (2002:59, meu grifo). (Embora, como demonstrarei adiante, num certo sentido, num certo sentido concordo como estes autores da tradição: de fato, o PD pode ser derivado do PI e do PC.) Ele se refere à facticidade "específica" como sendo "algo a posteriori". Essa tese, aparentemente inconciliável com (B), é, na verdade, um desdobramento ulterior: $\mathrm{O}$ autor já não está tratando do PD enquanto tal ou da alteridade como princípio, mas sim das alteridades específicas, particulares e contingentes, como fica claro nas expressões "o meu ato de fala" (p. 59 e p. 60), "facticidade específica" (p. 60). Ou seja, a tese é que, embora o Princípio da Diferença seja necessário (disso o autor não pode abdicar se pretende apresentar depois este Princípio como sendo universalíssimo), as diferenças concretas são contingentes. Em outras palavras, importa que haja contingências, mas quais contingências são atualizadas, isso é, obviamente, contingente. Nisso é certeiro o seu julgamento: " $\mathrm{O}$ ato contingente de fala, se realmente dedutivel, deixaria de ser contingente e tornar-se-ia necessário; contingência e dedutibilidade não são copossiveis " (2002, p. 5) (Isso só vale, é claro, se entendemos por dedutibilidade, neste caso, a inferência de axiomas lógicos, e não a inferência de premissas contingentes de onde se deduzem, obviamente, proposições igualmente contingentes: "Sempre que chove, Pedro fala de futebol, hoje chove = Pedro fala hoje de futebol" - têm-se aqui uma relação de dedutibilidade de contingentes).

\subsection{Princípio de Coerência (PC)}

Além desses dois princípios, o autor introduz o Princípio de Coerência, também chamado de Princípio de Não Contradição (PNC). Certamente os lógicos contemporâneos replicariam imediatamente lembrando da existência de sistemas lógicos paraconsistentes, onde tal princípio não é pressuposto. Nestes sistemas, 
porém, a negação é entendida num sentido bastante peculiar, e teríamos de decidir se essas lógicas realmente rejeitam o Princípio de Não Contradição, já que este princípio nega a contradição no sentido clássico, o que nos levaria a uma série de questões de ordem técnica. Por isso, deixo a discussão e aceito este princípio no sentido do autor, em especial saúdo a lembrança da estratégia, conhecida desde a escolástica e aperfeiçoada por Leibniz, de superação de aparentes contradições pela introdução de distinções. ${ }^{3}$

A minha concentração no PD se dá especialmente porque ele será o mais importante para a geração da antinomia que Cirne-Lima precisa para por seu sistema "em movimento".

\section{Auto-aplicação de Princípios e Antinomia}

Fundamental para a construção do sistema de Cirne-Lima é a antinomia gerada na auto-aplicação dos (momentos dos) Princípios da Metalógica, pois é ela que, semelhante ao sistema de Hegel, permitirá (ou exigirá) a passagem para a Filosofia da Natureza. Em primeiro lugar, importa destacar que um principio, no sentido do autor, é expresso por um enunciado considerado universalmente verdadeiro, portanto não é o mesmo que axioma ou premissa - premissas e axiomas são considerados verdadeiros relativos a um sistema formal, princípios (se é que tais existem) devem ser irrestritos, absolutos, não relativos. Seu ponto de partida é, então, a afirmação de que

Princípios, para serem verdadeiramente princípios, devem ser universalíssimos. Para serem universalíssimos, os primeiros princípios devem valer para todas as coisas e entidades, devem ser aplicados a todas as coisas, inclusive a si mesmos. Princípios universalíssimos devem ser, pois, também aplicáveis a si mesmos, devem valer de si mesmos. (p. 63)

Devemos, pois, segundo Cirne-Lima, aplicar os três princípios a si mesmos. Uma profunda dificuldade surge, pois se os princípios pretendidos devem ser universalíssimos (neste sentido especial), então isso já deveria ter sido levado em consideração na sua fundamentação - e como vimos no caso do PD, a sua fundamentação não foi universal, mas sim específica: só porque uma tautologia depende, em sua expressão, de um contingente ato de fala que é diferente da tautologia, isso não implica que tudo seja diferente de tudo.

A aplicação da Identidade a si mesma, bem como a coerência, segundo o autor, não é problemática, afinal "a Identidade é idêntica a si mesma, a Coerência é sempre coerente consigo mesma" (2002, p. 63). A antinomia surge na aplicação do segundo princípio, o da diferença, a si mesmo:

3 De fato, esta noção caiu muito em esquecimento, embora seja radical demais afirmar que ela "hoje não é mais utilizada em Lógica Matemática". Wolfgang Degen, por exemplo, exímio lógicomatemático alemão, docente da Universidade de Erlangen, é autor de uma grande obra (sua tese de livre-docência) sobre a Lógica Reduplicativa: Systeme der kumulativen Logik (Munich, Philosophia 1984). 
Se ela (a diferença) é diferente dela mesma, então, ela não é diferença e, não sendo diferença, ela é identidade. [...] Mas, se a diferença é idêntica a si mesma, então, ela, por isso mesmo, é diferença e exige ser vista e tratada como tal. A diferença é diferença e não identidade. (63)

\section{Destaco duas críticas, uma exterior e uma imanente:}

\subsection{Primeira crítica}

Em geral, os motivos dos lógicos contemporâneos para a rejeição da autoaplicação de todo e qualquer enunciado (seja ele um princípio ou não) são (1) a confusão entre a linguagem objeto e a metalinguagem e, (2) o desrespeito a estruturas sintáticas de toda e qualquer linguagem, inclusive a utilizada por Cirne-Lima na sua análise metalógica, onde surgem termos da linguagem objeto como "identidade", "diferença" e termos metalingüísticos como "tautologia", "verdade", "antinomia" e outros. Se ele pretende "se situar fora" do sistema lógico clássico, deveria atribuir novos significados aos termos que ele adotou dessa tradição.

Mas o problema não é apenas uma proibição (supostamente dogmática) dos lógicos de separar linguagem objeto da metalinguagem, mas sim a impossibilidade lógica de se fazer tal auto-aplicação. Se aplicamos o princípio de identidade, por exemplo, formulado numa notação usual como $\forall x(x=x)$, a si mesmo, teriamos algo como $\forall \mathrm{x}(\mathrm{x}=\mathrm{x})=\forall \mathrm{x}(\mathrm{x}=\mathrm{x})$. Mas, e nisto reside o problema mais profundo, o significado de "=" na primeira fórmula (a identidade de $\mathrm{x}$ consigo mesmo) não tem 0 mesmo significado do mesmo sinal "=" na segunda fórmula (a identidade da fórmula $\forall \mathrm{x}(\mathrm{x}=\mathrm{x})$ consigo mesma). No primeiro caso se trata da identidade de um indivíduo (Sócrates é Sócrates), no segundo da identidade de duas fórmulas ("'Sócrates é Sócrates' é logicamente equivalente a 'Sócrates é Sócrates'"). Este problema foi reconhecido por Russell: a afirmação de identidade na aritmética " $2+2=4$ " não tem o mesmo significado que a afirmação da identidade de classes " $A=B$ ", de modo que, a rigor, deveriam ser utilizados diferentes símbolos ou índices ${ }_{a \mathrm{r}} \mathrm{e}{ }_{\mathrm{dd}}$. Identidade aritmética (na Aritmética de Peano), significa "ter o mesmo antecessor" ou "ter o mesmo sucessor", enquanto na teoria de classes (Cantoriana) significa "ter os mesmos elementos". Aplicada a si mesma a fórmula perde o seu significado original, e assim, não foi aplicada a si mesma, mas sim, aplicou-se uma nova (e diferente!) fórmula à fórmula original. No caso do PI: a identidade de Sócrates com ele mesmo não é do mesmo tipo que a identidade afirmada do PI com ele mesmo, logo não se aplicou, a rigor, o PI a ele mesmo.

Em todo caso, reconheço que esta crítica requer um certo consentimento e comprometimento com as noções e procedimentos típicos da lógica contemporânea, a qual o autor poderia, basicamente, rejeitar. ${ }^{4}$ Passo, por isso, a uma objeção mais imanente, usando a própria estrutura argumentativa do autor.

\footnotetext{
Eu digo explicitamente que o autor "poderia" rejeitar, na forma hipotética, porque isso, felizmente, não me pareceu ser a sua posição. Pelo contrário, em várias passagens o autor reconhece o valor da análise lógico-analítica e demonstra conhecer e respeitar vários resultados estabelecidos na lógica contemporânea, como a antinomia de Russell, a distinção de niveis de linguagem e o teorema de Gödel. Não me é, todavia claro, no que consistiria o problema de uma entidade tão inofensiva como a classe vazia para Russell e Frege (p. 64).
} 


\subsection{Segunda crítica}

Para esboçar a segunda crítica é preciso relembrar que todos os predicados envolvidos nos princípios em questão parecem ter aridade 2: "ser idêntico a", "ser diferente de" e "ser coerente com":

PI) $\quad-\ldots$
PD) $\quad \neq \ldots$
PC) $\quad$ C ...

mas, que, como acima demonstrado, somente $\neq \mathrm{e} C$ de fato 0 são. A identidade é, a rigor, um predicado monádico: tudo é idêntico a si mesmo (é valido $\forall \mathrm{x}(\mathrm{x}=\mathrm{x})$ [0 $\mathrm{x}$ antes de "=" é o mesmo $\mathrm{x}$ que ocorre depois dele], mas não $\forall \mathrm{x} \forall \mathrm{y}(\mathrm{x}=\mathrm{y}))$. Somente numa linguagem com termos co-referenciais à identidade pode gerar uma fórmula válida. Além disso, é importante observar que em nenhum momento na fundamentação dos princípios foi estabelecido que a aplicação de um princípio significa que eles precisem ou possam ocorrer nos dois lados da fórmula livremente. Podemos aplicar o PD a ele mesmo, obtendo, por exemplo, a fórmula:

$$
\mathrm{PD} \neq \mathrm{PI}
$$

a qual não é nada antinômica. A antinomia surge (eu diria: forçosamente) da insistência da aplicação universal de todos os princípios sobre todos os princípios. A antinomia surge se consideramos que todos lugares dos argumentos têm de ser preenchidos validamente em todas as combinações possíveis (num total de $3^{3}=27$ combinações), dentre elas:

$\begin{array}{ll}\text { (F1) } & \mathrm{PI}=\mathrm{PI} \\ \text { (F2) } & \mathrm{PI}=\mathrm{PD} \\ \text { (F3) } & \mathrm{PI}=\mathrm{PC} \\ \text { (F4) } & \mathrm{PD} \neq \mathrm{PI} \\ \text { (F5) } & \mathrm{PD} \neq \mathrm{PD} \\ \text { (F6) } & \mathrm{PD} \neq \mathrm{PC} \\ \text { (F7) } & \mathrm{PC} \text { C PI } \\ \text { (F8) } & \mathrm{PC} \text { C PD } \\ \text { (F9) } & \text { PC C PC }\end{array}$

E aqui está o problema de toda argumentação: depois de fundamentar o PI no sentido $\forall \mathrm{x}(\mathrm{x}=\mathrm{x})$ (tudo é idêntico a si mesmo) não se pode aplicá-lo no sentido $\forall x \forall y(x=y)$ (tudo é idêntico a tudo). Isso requereria uma nova fundamentação (a qual me parece obviamente impossivel). O mesmo vale para o PD: depois de argumentar a necessidade da alteridade de um caso específico (da tautologia em relação ao ato de fala contingente), o autor aplica o princípio a todos os casos imagináveis. 
Aliás, se essa é a origem da antinomia, então, diferente do que Cirne-Lima afirma ${ }^{5}$ não apenas a aplicação da diferença a si mesma (F5) gera antinomia, mas até mesmo a Identidade, pois a identidade deveria ser idêntica à diferença (F2) e à coerência (F3). Repare-se que (F3) também é antinômico, e completamente independente do PD. É neste sentido específico que eu afirmei acima que concordava com Hegel no sentido de que a Diferença pode ser derivada da Identidade e da Coerência: dados PI e PC, vale que PI $\neq \mathrm{PC}$, o PI é diferente do PC.

Se insistimos, em nome da universalidade absoluta, que todos os princípios devem ser aplicados a tudo, teríamos nesta "orgia" combinatória, partindo apenas do PI e PC, infinitas antinomias, afinal, aplicando os princípios às próprias aplicações dos princípios (o que deveria ser necessário, posto que os principios se aplicam a tudo!), obtemos também, por exemplo (ainda sem uso do PD):

$$
\begin{aligned}
& (\mathrm{PI}=\mathrm{PI})=(\mathrm{PC}=\mathrm{PC}) \\
& (\mathrm{PI}=\mathrm{PI})=(\mathrm{PIC} \mathrm{PI}) \\
& (\mathrm{PI}=\mathrm{PI})=(\mathrm{PC} \mathrm{C} \mathrm{PC}) \\
& ((\mathrm{PI}=\mathrm{PI})=(\mathrm{PC} \mathrm{C} \mathrm{PC}))=((\mathrm{PI}=\mathrm{PI}) \mathrm{C}(\mathrm{PC} \mathrm{CPC}))
\end{aligned}
$$

e assim ad infinitum. Esses monstros lógicos deixam claro que há algo fundamentalmente errado na tese da livre e necessária combinação de todos os princípios em auto-aplicação. O cerne da minha crítica está na questão, portanto: como preencher adequadamente "__ " e "..." num sentido sensato. Fundamental nessa determinação é que se leve em conta o sentido desses três princípios no momento da sua introdução/fundamentação. Não se pode fundamentar a necessidade de um princípio num determinado sentido e depois, ao aplicar tal princípio, fazer livre uso de qualquer outro sentido. "Tudo é idêntico a si mesmo" $(\forall x(x=x))$ foi, a rigor, o sentido da argumentação de Cirne-Lima para fundamentar o PI ("A=A", "Sócrates=Sócrates", "Universo=Universo") (p. 57) e é neste sentido que "ninguém jamais discordou disso, ninguém consegue pôr isso em dúvida" (p. 57), afinal, tudo isso poderia ser re-escrito monadicamente "AI", "Sócrates $I$ ", "Universo I", e, portanto, é somente neste sentido que ele pode ser aplicado. Enquanto predicado binário a diferença só poderia ser aplicada, como argumentamos acima, numa linguagem onde existissem termos co-referenciais, por exemplo:

Túlio $=$ Cícero

Pelé $=$ Edson Arantes do Nascimento

ou, se quisermos permanecer na aplicação de Cirne-Lima:

Princípio de Identidade $=$ Prinzip der Identität

5 "Quanto ao Principio de Identidade e ao Princípio da Coerência não há problemas. A Identidade é sempre idêntica a si mesma, a Coerência é sempre coerente consigo mesma. O primeiro e o terceiro subprincipios são, como de imediato se vê, auto-aplicáveis e podem, sob este aspecto, ser considerados como momentos de um principio universalissimo." (p. 63) 
(supondo que "Princípio de Identidade" e "Prinzip der Identität" fossem termos sinônimos de uma só linguagem). Este mesmo princípio não pode ser usado depois, arbitrariamente, no sentido de (F3) PI = PC, que é uma aplicação de $\forall x \forall y$ $(\mathrm{x}=\mathrm{y})$ ao invés de $\forall \mathrm{x}(\mathrm{x}=\mathrm{x})$, já que dois argumentos diferentes são introduzidos antes e depois do "=", o que seria impossível posta a natureza monádica da identidade.

De modo semelhante, o que permitiu a introdução do PD foi justamente a percepção da necessidade da alteridade - mas se diferença significa alteridade, é claro que não se pode preencher os dois lados de " $\neq$ " com a mesma entidade. Formalmente este sentido se expressaria numa fórmula como $\forall \mathrm{x} \forall \mathrm{y}(\neg(\mathrm{x}=\mathrm{y}) \rightarrow$ $\mathrm{x} \neq \mathrm{y})$, que, no fundo, nada mais é do que uma definição do signo " $\neq$ ". Em todo caso, se isso é respeitado, temos todos os princípios sendo aplicados a si mesmos sem nenhuma antinomia, como em (F1) PI = PI, (F4) PD $\neq$ PI e (F 7) PC C PI, além de outras formulas válidas como

$$
\begin{aligned}
& P D=P D \\
& P C=P C \\
& P I \neq P D \\
& P I \neq P C \\
& P D \neq P C \\
& P I C P I \\
& \text { PI } C \text { PC } \\
& \text { PI } C \text { PD }
\end{aligned}
$$

Observe-se que (F14) e (F15) são válidas posto serem aplicações de $\forall \mathrm{x}(\mathrm{x}=\mathrm{x})$, (F16) - (F18) são válidas, pois são aplicações de $\forall x \forall y(\neg(x=y) \rightarrow x \neq y)$. E, finalmente, o princípio de coerência, que na argumentação informal de Cirne-Lima assume o sentido $\neg(\mathrm{A} \wedge \neg \mathrm{A})$, é respeitado por (F19) - (F20), pois de nenhuma delas se deriva uma contradição.

Thomas Kesselring, ao perceber que o puro PD não garante a antinomia por si só, posto que "PD $\neq$ PI" é inofensivo, reinterpreta o PD (em correspondência não publicada) num sentido muito peculiar (Princípio de Diferença de Kesselring - $\left(\mathrm{PD}^{\mathrm{K}}\right)$ : Diferença significa ser diferente de si mesmo (sic!), ou seja, $\forall \mathrm{x}(\mathrm{X} \neq \mathrm{X})$, tornando assim toda a argumentação forçosamente (artificialmente) antinômica. Vale lembrar que, se esse fosse o sentido do PD, então não valeria a argumentação de Cirne-Lima para justificar a introdução deste princípio, que se baseia na alteridade que subsiste entre o contingente ato de fala e a verdade da tautologia. Para fundamentar $\circ \mathrm{PD}^{\mathrm{K}}$ Cirne-Lima não bastaria mostrar que a tautologia não é a tautologia e quধ , ato de fala contingente não é o ato de fala contingente, 0 que já é impossivel, mas sim, pior, que tudo no universo é diferente de si mesmo $(\forall x(x \neq x))$, o que, certamente, não pode ser feito sem extrapolar os limites da racionalidade, o que Cirne-Lima, felizmente e diferente de Kesselring, não pretende fazer. 
É preciso aqui fazer uma pequena excursão sobre o significado do conceito de antinomia para explicar por que uma argumentação artificialmente antinômica deve ser rejeitada. Em geral, por antinomia entende-se, em lógica, um resultado inusitado e obviamente falso que se chega, quando se parte de premissas ou axiomas (ou princípios) considerados consensualmente válidos. Ou seja, uma antinomia nunca é o ponto de partida, mas sim de chegada numa cadeia dedutiva. A antinomia de Russell, por exemplo, é a inferência da fórmula contraditória $R \in R \leftrightarrow$ $R \notin R$, a qual, e isso é fundamental, foi deduzida logicamente de uma fórmula aparentemente inofensiva como $\forall x \exists y(x \in y \leftrightarrow F x)$ - o chamado axioma de compreensão, que simplesmente afirma que a todo predicado corresponde uma classe. Esse uso consagrado é também o seu sentido original: as antinomias do movimento de Zenão, por exemplo, são resultados inusitados e absurdos a partir de uma reflexão de premissas aparentemente não problemáticas. Neste sentido, a proposta de Kesselring de que diferença significa "ser diferente de si mesmo" não pode gerar uma antinomia pelo simples fato de que não parte de premissas racionalmente aceitáveis. Ela simplesmente propõe arbitrariamente uma contradição como ponto de partida. Se esse é o sentido do PD, então, novamente, a fundamentação de Cirne-Lima seria errônea, pois esta se baseou na intuição racional de que diferença significa alteridade de coisas diferentes de si mesmo. Dada a interpretação de Kesselring, pergunta-se por que ele não propõe então logo que PI significa que "tudo é idêntico a coisas diferentes" e que o PC significa "dois princípios incoerentes são coerentes".

E o que fazer quando se encontra uma antinomia? Quando se descobre uma antinomia o único procedimento racional adequado (e por isso praticado pelos lógicos) é uma re-avaliação dos axiomas ou do sistema lógico do qual se partiu. A descoberta da antinomia de Russell foi útil, pois ensinou os lógicos que o axioma $\mathrm{V}$ de Frege estava errado, embora ele parecesse, para muitas gerações de lógicos, uma obviedade. A razão se engana. Alguns proporiam uma troca de sistema lógico (p. ex. da Costa, 1999, p. 259s), outros uma axiomatização da teoria dos conjuntos (p.ex. Zermelo-Fränkel, Neumann-Bernays-Gödel, e outros). Em todo caso, uma antinomia não deve levar a uma expansão do sistema (acréscimo de dimensões), como o faz Cirne-Lima, bem na tradição idealista (não só de Hegel, mas também de Bradley e do jovem Russell), mas sim a uma maior restrição axiomática, uma redução do sistema. A minha sugestão seria: suspender a validade do PD irrestrito. Afinal, como escreve Cirne-Lima (2002, p. 64) com razão: "O que não podemos, sem perder a racionalidade, é ficar no vaivém da antinomia". E eu acrescentaria: não podemos ter racionalidade, estipulando a priori e intencionalmente uma antinomia. Nossos caminhos se encontram na conviç̧ão que a racionalidade é boa, base de toda nossa discussão. 
No início acentuei a positividade da iniciativa original de Cirne-Lima, e gostaria de encerrar, esboçando uma espécie de apologia do que me parece ser um bom sentido das suas idéias fundamentais. Algumas reflexões de Cirne-Lima são valiosas para algo como uma propedêutica transcendental da lógica, ou até mesmo para uma epistemologia da lógica. Deve ficar claro, em primeiro lugar, que as reflexões estão "fora" do campo das lógicas particulares (embora a argumentação seja lógica, no sentido apresentado no início do artigo, de que não se pode argumentar "fora" da lógica), na medida em que são pressupostos ao mesmo tempo pragmáticos e transcendentais da lógica. Os três princípios propostos têm, de fato, algo de interessantemente fundamentais se compreendidos no sentido de condições de possibilidade cognitiva de compreensão da lógica.

Na lógica, dir-se-ia, nenhum dos três princípios é realmente fundamental. Quanto ao PI: Pode-se, por exemplo, construir uma lógica de predicados de primeira ordem sem identidade. A lógica proposicional também é construída normalmente sem identidade. Aliás, o próprio silogismo aristotélico não fazia uso da identidade. Quanto ao PD: o conceito de diferença pode ser definicionalmente eliminado se tivermos uma linguagem com os termos de igualdade e negação: ao invés de $A \neq B$, pode-se dizer o mesmo com $\neg(A=B)$. A tese de que a diferença é ineliminável é, neste sentido, simplesmente errada. Finalmente, quanto ao PC ou PNC: Constitui justamente uma das grandes contribuições da filosofia e lógica brasileira os trabalhos de Newton da Costa na área da lógica paraconsistente, onde se tem um sistema lógico dedutivo não-trivial sem o PNC. Nenhum dos três principios parece fundamental para a lógica.

Mas, e isso Cirne-Lima viu 'com clareza, talvez eles sejam fundamentais na metalógica. Num sentido muito fundamental, todo sistema lógico faz uso de termos (sejam eles constantes, operadores ou variáveis) que permanecem constantes durante um procedimento de inferência, ou até mesmo ao longo de uma fórmula: $\rightarrow$ deve ser compreendido como idêntico a $\rightarrow$ em qualquer lugar e situação de ocorrência. O reconhecimento da identidade permanente deste símbolo é condição de possibilidade de compreensão da lógica, uma espécie de condição de possibilidade do fazer lógico. Em toda prova lógica ocorrem na conclusão termos que necessariamente ocorreram nas premissas ou nos passos inferenciais: a preservação da verdade (identidade da verdade através do processo de inferência) pressupõe a preservação do significado de alguns termos na seqüência de fórmulas da prova. O mesmo vale para a diferença: Não existe nenhuma lógica com um só termo fundamental: mesmo que se use uma só constante lógica (como a barra de Sheffer), esta constante é diferente das proposições que ela conecta. E na lógica de predicados de primeira ordem é fundamental a distinção entre predicado $(F)$ e indivíduo (x), numa terminologia Fregeana, entre função e objeto. Não há nem pode haver uma lógica que seja a mera iteração e combinação de um só conceito. $\mathrm{E}$, finalmente, a noção de inferência de uma fórmula $\phi 1$ a partir de outra fórmula $\phi 2(\phi 2 \mid-\phi 1)$ só é significativa em qualquer cálculo na medida em que ele não é 
trivial, isso quer dizer, que nem todas as fórmulas possam ser deduzidas dos axiomas do sistema. Um sistema onde tudo é dedutivel não é mais lógica. Entre todas as fórmulas dedutíveis num sistema tem de subsistir uma relação de coerência (não entendida com não-contradição no sentido suspenso pela lógica paraconsistente): se $\phi 1$ e $\phi 2$ são diferentes e ambas dedutíveis num sistema, então $\phi 1$ e $\$ 2$ devem ser coerentes (compatíveis), sob pena de trivialização do sistema.

Um filósofo da tradição dialética tem certamente prazer em antinomias, pois elas lhe permitem o desenvolvimento. A grande vantagem da postura dialética é a sua capacidade de interpretar objeções como se fossem contradições do seu sistema, e assim, toda objeção é interpretada não como objeção, mas sim como "complemento" bem-vindo ao seu sistema, ou seja, o sistema dialético consegue integrar toda e qualquer crítica como parte imanente. Mas essa força também é, penso eu, dialeticamente, sua fraqueza, pois representa uma estratégia de imunização - e, como diria Popper - não há nada mais indesejável na ciência do que uma teoria imune a revisões.

\section{Referências}

CIRNE-LIMA, C. O "Absoluto e o sistema: Agostinho, Tomás de Aquino e Hegel" em Oliveira M. \& Almeida C. O Deus dos Filósofos Modernos. Vozes, Petrópolis: 2002.

DA COSTA, N. Conhecimento Cientifico. São Paulo, Discurso Editorial: 1999.

DEGEN, W. Systeme der kumulativen Logik. Munique, Philosophia: 1984.

HAACK, S. The Philosophy of Logics.

QUINE W. v.O. Philosophy of Logic. Harvard University Press, 1970.

RUSSELL, B. The Principles of Mathematics [PoM] (1903). Routledge, London: 1992.

BERNAYS, P. Sur le platonisme dans les mathématiques (1935). Em: L'Enseignement Mathématique, Vol. XXXIV, Nr. 1-2.

WITTGENSTEIN, L. Tractatus logico-philosophicus. Suhrkamp, Frankfurt am Main: 1989. 